\title{
APLIC@TIVOS PARA TABLETS: EDUCAR PARA E COM AS TECNOLOGIAS DIGITAIS
}

\author{
Debora Valletta - PPGEDU/PUCRS, dvalletta@uol.com.br
}

\begin{abstract}
Resumo. A inquietação e as diversas necessidades de ordem social e dialética dos educadores no século 21 favorece um olhar sob a perspectiva do uso e seleção de aplicativos (Apps) para tablets elou smarthphones. A percepção dessas articulações e diálogos pode ser percebida por meio da linguagem multimodal que as atuais gerações vêm construindo. Nesse contexto, este artigo visa discutir sobre a necessidade de um olhar critico quanto as funcionalidades que as ferramentas de comunicação $e$ compartilhamento oferecem para "interagir" com as crianças e os jovens. Trata-se de uma pesquisa qualitativa de caráter exploratório, desenvolvida a partir de um estudo de caso promovido em uma escola privada que possui no seu arcabouço diretivo a inclusão de Tecnologias Digitais na prática docente. O objetivo do trabalho foi levantar elementos para se refletir acerca do uso e potencialidades pedagógicas (downloads/baixar Apps) de 427 Apps. Tal reflexão busca auxiliar os professores a tecer e articular possibilidades para o uso destas ferramentas no educar para e com as mídias, tendo como foco principal apoiar a ação docente ao trabalho discente face às demandas geradas pela adoção de dispositivos móveis na Educação Básica.
\end{abstract}

Palavras-chave: Apps; dispositivos móveis; tablets; Educação para e com as mídias; Formação de professores

\section{APLI@TION FOR TABLETS: EDUCATING FOR AND WITH DIGITAL TECHNOLOGIES}

\begin{abstract}
Restlessness and the diverse needs of social and dialectic of educators in the 21 st century favors a look from the perspective of the use and selection of applications (Apps) for tablets and / or smartphones. The perception of these joints and dialogues can be perceived through the multimodal language that current generations have been building. In this context, this article aims to discuss the need for a critical look at how much functionality that sharing and communication tools offer to "interact" with children and young people. This is a qualitative exploratory research, it was developed from case study promoted in a private school that it has in its governing framework the inclusion of Digital Technologies in teaching practice. The objective was identifying elements for reflecting on the use and pedagogical potential (downloads / download Apps) 427 Apps. This discussion aims to help teachers to weave and articulate possibilities for using these tools in education and education with the media. Main focus supports the teaching activities to student work against the demands generated by the adoption of mobile devices in Basic Education.
\end{abstract}

Keywords: Apps; mobile devices; tablets; Education and the media; Teacher training

\section{Introdução}

Os meios de comunicação integraram e interagem de forma definitiva com a sociedade, e cada vez mais articulam as mediações deste diálogo com a escola, o que acabou incidindo na maneira em que se imbricam as áreas de educação e comunicação, 
possibilitando o uso das Tecnologias Digitais ${ }^{1}$ (TD), exigindo-se então um novo olhar para os tablets e os Apps disponíveis para esses artefatos.

Segundo Livi e Silveira (2006, p. 32) Apps são "as aplicações criadas para solucionar problemas específicos e que se valem das facilidades oferecidas pelo software básico".

Em/nessa perspectiva, percebe-se o quanto ainda é preciso e necessário entender a complexidade dos processos que estão envolvidos nas relações entre o sujeito e a mídia. Como bem coloca Jenkins (2009, p. 284)

As crianças são participantes ativas nessa nova paisagem midiática, encontrando a própria voz [...] declarando seus próprios direitos, mesmo de entidades poderosas e, às vezes, sem o conhecimento dos pais [...] estão traçando novas estratégias para lidar com a globalização, com as batalhas em torno da propriedade intelectual e com os conglomerados de mídia.

O uso das mídias no contexto educacional também é apontado por Moran (2007, p. 5),

A educação escolar precisa compreender e incorporar mais as novas linguagens, desvendar os seus códigos, dominar as possibilidades de expressão e as possíveis manipulações. É importante educar para usos democráticos, mais progressistas e participativos das tecnologias, que facilitem a evolução dos indivíduos.

A educação das crianças e jovens não pode estar alheia ao novo contexto socioeconômico-tecnológico, cuja característica geral não está mais na centralidade da produção fabril ou da mídia de massa, mas na informação (re) produzida como nova infraestrutura básica. Mediados por meio dos recursos digitais ${ }^{2}$ que têm possibilidades de interações entre usuários a qualquer lugar e a qualquer hora através dos Apps que funcionam conectados com à Internet.

Castells (2003, p. 164) afirma que a "Internet oferece a possibilidade de criação coletiva, interativa, conjunta, por meio de práticas de grupo que permitem a pessoas distantes no espaço pintar, esculpir, desenhar, compor e produzir juntas, em interação e muitas vezes em contradição." Além disso, é importante salientar que essas ações/comportamento por meio da Internet foram/estão sendo potencializadas devido aos dispositivos móveis multifuncionais que propicia a interação e a comunicação entre os grupos de usuários.

Como é possível a cultura escolar versus cultura midiática promoverem este diálogo de forma a produzir uma mudança no ambiente escolar, de modo que, os alunos desenvolvam tanto a habilidade tecnológica para o uso dos tablets, quanto a habilidade cognitiva e social a partir da capacidade ${ }^{3}$ de operação dos Apps à qual permitem interações entre pessoas, conteúdos e artefatos (equipamentos), e que atualmente estão disponíveis em massa para os dispositivos móveis?

Este é um dos desafios para os pesquisadores e educadores, refletir e buscar entender a complexidade de como as tecnologias e a mídia inserida na cultura escolar podem modelar as crianças e/ou jovens, desenvolvendo suas potencialidades no falar, no agir, no comportamento e em seu processo criativo. Podendo auxiliar, inclusive, na questão identitária. A relação entre o consumo e a identidade configura um caráter não apenas individual, mas também social, como bem coloca Hall (2001, p. 75),

[...] Quanto mais a vida social se torna mediada pelo mercado global de estilos, lugares e imagens, pelas viagens internacionais, pelas

\footnotetext{
${ }_{2}^{1}$ Apesar da sigla TIC ser amplamente usada na área de Educação, utilizou-se neste texto o

${ }^{2}$ Aqui entenda recursos digitais como o hardware (tablets, entre outros) e o software (Apps).

${ }^{3}$ No sentido de competências de educar para e com as mídias.
} 
imagens da mídia e pelos sistemas de comunicação globalmente interligados, mais as identidades se tornam desvinculadas desalojadas - de tempos, lugares, histórias e tradições específicos e parecem 'flutuar livremente.

Assim, é preciso oferecer a esses sujeitos uma forma efetiva de uso tecnológico e comunicacional, uma prática educativa e social, pois a educação verdadeira não está na exclusiva transferência ou transmissão do conhecimento de um sujeito a outro (professor-aluno), mas a sua coparticipação no ato de compreender a significação do significado.

Para Freire (1996, p. 139) "toda comunicação é comunicação de algo, feita de certa maneira em favor ou na defesa, sutil ou explícita, de algum ideal contra algo e contra alguém, nem sempre claramente referido". Nesse sentido, faz-se necessário criar oportunidades na escola para que o docente possa propiciar situações de aprendizagem para o desenvolvimento do senso crítico para e com as mídias com os estudantes.

Isso significa que, para além da inserção do uso educativo das mídias em sala de aula, há possibilidades de integrar os objetos de conhecimento da matriz de referência do Exame Nacional do Ensino Médio (ENEM), Prova Brasil entre outras avaliações em larga escola associados a demanda dos Parâmetros Curriculares Nacional (PCNs) diretamente conectado com as habilidades e competências cognitivas, sociais entre outras.

\section{Aspectos metodológicos da pesquisa}

Para o desenvolvimento do trabalho realizou-se como metodologia de pesquisa o estudo de caso. Participaram deste estudo 4 auxiliares de Tecnologias Educacionais (sujeitos da pesquisa) que deram apoio técnico e pedagógico na formação continuada de professores ofertada pela instituição de ensino. Foi aplicado um questionário semiestruturado utilizando a ferramenta Google Formulário para coletar e analisar todas as Apps que foram baixadas/instaladas nos iPads $^{4}$, denominado pelos sujeitos da pesquisa de "TESTES" durante o segundo semestre de 2013 a janeiro de 2015. Ressalta-se também que, esses 4 sujeitos também participaram do projeto de implementação da metodologia proposta por VALLETTA (2014) para selecionar Apps para os iPads. Então, os sujeitos da pesquisa receberam uma lista que fora levantada pela pesquisadora contendo o nome dos primeiros 427 Apps que estavam na lista de "comprados" da Apple Store (2013 a 2015) e disponibilizados na "nuvem", em arquivo no formato de Excel (software que permite editar planilhas eletrônicas).

Ao analisar as aplicações verificou-se a comunicação visual e a ferramentas disponíveis dentro dos Apps. Portanto, a amostra da análise foi intencional. Nota-se uma representação pictórica atraente e dinâmica ${ }^{6}$ para a criança e/ou jovens que baixam (fazem downloads) essas aplicações em seus dispositivos móveis.

Nesse sentido, esclarece-se que, em termos de procedimento de trabalho, fez-se uma seleção (exploratória) de alguns Apps que ilustram os tipos de ferramentas que

\footnotetext{
${ }^{4}$ iPad é um dos tablets disponíveis no mercado. Funciona com o sistema operacional iOs e foi o modelo de tablet adotado pela instituição de ensino.

${ }^{5} \mathrm{O}$ termo refere-se a computação nas nuvens. Neste artigo utilizou-se o sistema $i C l o u d$ da Apple, ou seja, um tipo de serviço disponibilizado via Internet que permite armazenar arquivos diversos e que consiste em acessá-los de qualquer lugar a qualquer hora - desde que o dispositivo (tablets, notebooks entre outros) esteja conectado na Internet.

${ }^{6}$ No sentido de ferramentas que permitem compartilhar e colaborar, por exemplo, as redes sociais.
} 
permitem compartilhar e colaborar com outros usuários por meio de um tablet conectado à Internet. Trata-se de uma categorização preliminar para analisar o tipo de conteúdo a ser compartilhado com foco nas habilidades sociais, por exemplo, expressar opinião.

Tal tipologia permitiu ainda, uma análise crítica dos Apps para verificar como o conteúdo é apresentado, ou seja, de forma estática ou em movimento. A interface gráfica como a informação é exibida ou gerada é igualmente de grande importância para que o professor/adulto possa avaliar a possibilidade de uso dos Apps em relação ao ato de educar para e com as mídias na escola e/ou fora dela.

\section{A tipologia pressuposta dos Apps e suas ferramentas}

De acordo com os estudos do Report Mobile (2013) 37\% dos brasileiros entrevistados compraram/baixaram Apps em seus smartphones. Já o último relatório da Ofcom "Children and Parents: Media Use and Attitudes Report" disponibilizado no final do ano de 2013 aponta tendências quanto os novos hábitos do uso de dispositivos móveis e Apps. A partir do exposto, pressupõe-se a importância de refletir acerca do uso, o consumo e em especial, as ferramentas de comunicação para compartilhar os conteúdos disponíveis dentro dos Apps.

Um App específico pode tornar o sujeito capaz de apenas ver, apenas ouvir, ver e ouvir, ver e ler, ver e colaborar, ver e compartilhar ou se engajar em alguma outra combinação dessas. Assim, pressupõe-se que a comunicação visual associada as ferramentas de comunicação e interação social disponíveis nos Apps podem atuar como possibilidades de aprendizagem coletiva e colaborativa entre o sujeito que aprende e ensina para educar com e para as mídias. Partindo desse pressuposto, refletir sobre o uso e consumo desses Apps no contexto fora do ambiente escolar também constitui-se numa maneira de se realizar um estudo crítico sobre esse tipo de mídia. Percebe-se a importância da presença e acompanhamento dos pais e/ou comunidade escolar para participação ativa no processo educativo para e com as mídias, como bem coloca Carlsson e Feilitzen (2009, p. 12) no relatório da UNESCO,

É fundamental o envolvimento da família e da comunidade na discussão do conteúdo da mídia, como é indispensável a discussão pelas escolas dos efeitos da mídia. A formação de uma mentalidade crítica constitui condição fundamental para a reeducação da mídia. Sem essa consciência, não será possível desenvolver a capacidade de discernir e de perceber o sentido de uma mensagem. Por outro lado, desenvolver nos alunos a capacidade de discernimento concorre para fazer ver aos produtores e responsáveis pela veiculação de alcance coletivo que a mídia é um bem público e, como tal, precisa levar em conta os valores éticos e as aspirações de uma determinada sociedade.

Observou-se que as ferramentas mais comuns encontradas nos Apps que permitem compartilhar conteúdos com outros usuários foram: e-mail, Dropbox, Facebook, Twitter e YouTube.

$\mathrm{Na}$ sequência selecionou-se os Apps de acordo com a taxonomia de Bloom Digital a partir do seu nível mais elevado, ou seja, $\operatorname{criar}^{7}$ (OVERBAUGH; SCHULTZ, 2009). Por outro lado, no modelo proposto por Anderson et al. (2001) cada expectativa de aprendizagem é associada a uma, dentre várias combinações possíveis entre os processos de construção do conhecimento e o desenvolvimento das habilidades

\footnotetext{
${ }^{7}$ Os Apps foram classificados a partir da projeção de estudos de cada nível de ensino e faixa etária para desenvolver e produzir novas ideias.
} 
cognitivas. É importante salientar que os estudos destes autores estão relacionados à Taxonomia de Bloom e Krathwohl de $1956^{8}$.

Conforme a análise realizada pelos sujeitos da presente pesquisa, os Apps são recategorizados de acordo com a necessidade das expectativas de aprendizagem dos projetos pedagógicos e/ou atividades complementares/apoio ao discente por meio da metodologia proposta por VALLETTA (2014).

\section{Discutindo alguns resultados}

Inicialmente, apresentamos alguns resultados para o uso e potencialidades pedagógicas relativos ao tipo de ferramenta de compartilhamento dos conteúdos, objeto de conhecimento e possibilidades de categorização conforme o planejamento dos projetos pedagógicos.

A partir do uso de procedimentos de análise textual discursiva de Moraes e Galiazzi (2007) foram analisados 427 Apps. Parte dos Apps podem criar elementos com potencial para compartilhar conteúdos. Esses totalizaram 24,5\% (105) do total, enquanto 75,5\% (323) dos Apps não possuem ferramentas de compartilhamento. Tal resultado mostra que $24,5 \%$ dos Apps poderiam ser usados de forma educativa pelo professor - um conteúdo compartilhado entre os usuários poderia servir como um "gancho" para fomentar uma discussão em sala de aula.

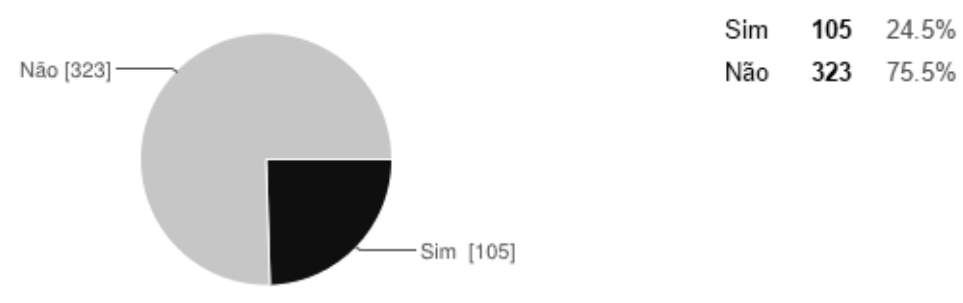

Figura 1- Quantidade de Apps que possui ferramentas de compartilhamento de conteúdos

Se analisarmos a figura 2, nota-se que o Facebook e o Twitter destacam-se entre as principais ferramentas para compartilhar informações e/ou conteúdos com outros usuários.

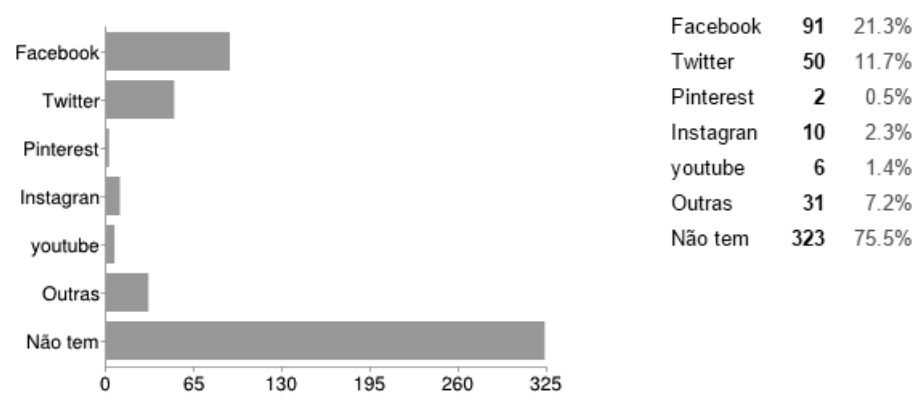

Figura 2- Tipos de ferramentas para compartilhar dentro das Apps

Como pode ser observado na figura 2, a soma dos resultados de todas as ferramentas do tipo "redes sociais" esteve presente em pelo menos metade das Apps. Nesse sentido, há evidências de que as ferramentas sociais podem exercer influência quanto aos hábitos e comportamento dos usuários. Algumas estão "disponíveis" para compartilhar e interagir conteúdos de autoria (edição de foto) ou ranking de pontuação para jogos digitais como, o App Candy $\mathrm{Crush}^{9}$.

\footnotetext{
${ }^{8}$ Ver discussão em Ferraz e Belhot (2010).

${ }^{9}$ Candy Crush é um game cujo objetivo é combinar “cores/doces" iguais para eliminá-los.
} 
As ferramentas sociais, nesta perspectiva, enquanto práticas pedagógicas inovadoras poderiam ser associadas às atividades desenvolvidas em sala de aula em que os docentes ${ }^{10}$ utilizam Apps para criar histórias em quadrinhos. Após produção e socialização entre a turma, criar uma hashtag\# $\#^{11}$ sobre o trabalho e posteriormente compartilhar os conteúdos ${ }^{12}$ nas redes sociais. Desta forma, propiciar situações de aprendizagem para questões associadas aos direitos e deveres nos ambientes virtuais, possibilita aos estudantes a reflexão e a análise crítica sobre os conteúdos que são compartilhados em rede.

Considerando o total de 427 Apps presentes no instrumento de coleta de dados, foi possível identificar: $291(68 \%)$ do tipo tutorial; 261 (61\%) exercício e prática e 60 (14\%) que permite a criação de modelos, por exemplo, que podem simular uma reação química. No caso da figura 3 apresenta-se os resultados de ferramentas de apoio para complementar as atividades em sala de aula.
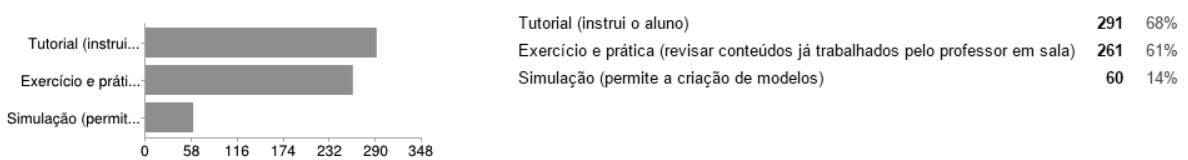

Figura 3- Tipo de aplicativo

Além disso, analisou-se a relação dos Apps e as possibilidades de uso nos diferentes níveis/áreas de ensino da Educação Básica. A maioria das Apps são classificadas para crianças entre a faixas etária de 4 a 6 anos, conforme é destacado na figura 4. Dessa forma, emerge o seguinte questionamento: de que forma educadores podem propiciar situações de aprendizagem integrando TD e móveis no cotidiano dessas crianças na escola?

Carlsson e Feilitzen (2009, p.27) apontam que

uma vez que a participação na mídia é uma forma de um indivíduo expressar suas opiniões acerca aquilo que o afeta, daí influenciando a sociedade, a participação da criança em questões sociais de relevância para ela automaticamente dá maior importância ao seu papel na sociedade, o que, por sua vez, a torna mais visível na mídia.

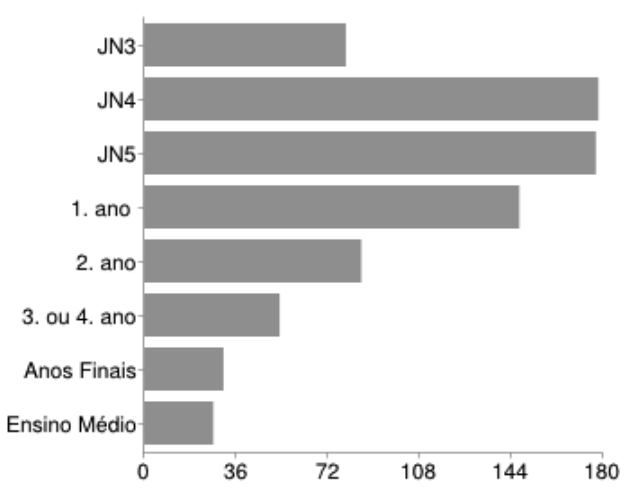

$\begin{array}{lrr}\text { JN3 } & \mathbf{7 9} & 18.5 \% \\ \text { JN4 } & \mathbf{1 7 8} & 41.6 \% \\ \text { JN5 } & \mathbf{1 7 7} & 41.4 \% \\ \text { 1. ano } & \mathbf{1 4 7} & 34.3 \% \\ \text { 2. ano } & \mathbf{8 5} & 19.9 \% \\ \text { 3. ou 4. ano } & \mathbf{5 3} & 12.4 \% \\ \text { Anos Finais } & \mathbf{3 1} & 7.2 \% \\ \text { Ensino Médio } & \mathbf{2 7} & 6.3 \%\end{array}$

Figura 4 - Quantidade de Aplicativos em proporção aos níveis de ensino

Nesse sentido, a pesquisa empírica apresenta evidências que sinaliza para a sociedade em geral o olhar crítico frente a esse tipo de mídia. Principalmente porque as crianças e os jovens estão cada vez mais cedo tendo oportunidades de acesso aos tablets e seus Apps.

\footnotetext{
${ }^{10}$ Principalmente os docentes com formação na área de Linguagem, Códigos e suas Tecnologias.

${ }^{11} \mathrm{O}$ símbolo \# é usado pelos usuários nas redes sociais para indexar um determinado assunto ou frase nas plataformas do Facebook, Twitter entre outros. Por exemplo: \#horáriodeverão

${ }^{12}$ Projetos sobre O uso consciente da água, Sustentabilidade entre outros.
} 
Numa outra direção de análise, ou seja, em relação (todos os Apps apresentados na matéria) as possibilidades de usar os Apps como apoio complementar nas atividades em sala de aula por áreas do conhecimento, temos:

- Linguagens, Códigos e suas Tecnologias: 41\%

- Matemática e suas Tecnologias: 18\%

- Ciências da Natureza e suas Tecnologias: 10\%

- Ciências Humanas e suas Tecnologias: 4\%

- Todas as quatro áreas do conhecimento ${ }^{13}: 27 \%$

A percepção dessas articulações entre os Apps, funcionalidades de suas respectivas ferramentas e objetos de conhecimento sugerem possibilidades de representações prático-pedagógicas mais inovadoras no processo de ensino $\mathrm{e}$ aprendizagem associados as TD.

Prensky (2010) destaca o papel das TD no contexto atual, pois elas oferecem diversos tipos de ferramentas para que o aluno possa aprender sozinho.

\section{Considerações finais}

Desde os estudos da década de 90 acerca dos efeitos da mídia na sociedade já havia indícios de que existem outros mecanismos que não apenas a televisão como transmissor e receptor de informações. Nesse sentido é importante ressaltar que após o advindo da Internet e seus serviços as informações passaram a ser compartilhadas em apenas "um clique", de forma veloz e sem controle.

Por outro lado, Santos (2011, p. 3), nos remete a refletir sob algumas das inquietações motivadoras deste artigo.

Apesar de parecer muito simples, e de depender apenas de um clique, o ciberativismo - que nasce com a entrada de ativistas na rede -, vem com uma proposta de conscientização através da internet. Na maioria dos casos uma movimentação que começa na internet e acaba nas ruas. E para isso não basta apenas o ciberativista, mas o ativista "real" também.

Não seria uma oportunidade para educar crianças e jovens para e com esse tipo de mídia (Apps), já que essas gerações de nativos digitais nasceram entre os "arranhacéus" da convergência digital?

Jenkins $(2009$, p. 30) em sua obra Cultura da Convergência é enfático quando afirma que "a convergência não ocorre por meio de aparelhos, por mais sofisticados que venham ser [...] ocorrem dentro dos cérebros de consumidores individuais e em suas interações sociais com outros [...] o consumo tornou-se um processo coletivo".

As TD podem criar elementos que possibilitam as crianças, jovens e adultos ter o conhecimento imediato de um fato, comentário postado nas redes sociais entre outros tipos de conteúdo, além de ter a possibilidade de "interagir" em tempo real.

Outro aspecto, também exposto ao longo do texto no que diz respeito a participação da família/adultos no processo educativo. A questão é preocupante com as crianças e os jovens, e os educadores do século 21 necessitam refletir e pensar sob o ponto de vista desses adultos no que se refere ao ato de sistematizar as atividades com o uso e o consumo desse tipo de mídia, portanto, planejar, organizar e orientar os estudantes a fim de educá-los para e com as mídias.

Segundo a App Annie (2014) há mais de 1 bilhão de Apps disponíveis para os sistemas iOs (Apple) e Android (Samsung, Positivo entre outras marcas). Se tomarmos

\footnotetext{
${ }^{13}$ São Apps que podem ser usados em qualquer área do conhecimento, por exemplo, Simple Mind Map - criar mapas mentais.
} 
a informação como ponto de partida, ressalta-se a importância de orientar o ecossistema escolar para selecionar Apps que possam favorecer à pesquisa escolar no contexto da cibercultura.

Lembramos ainda que o conceito de Tecnologia Educacional das décadas de 70 e 80 tratava apenas como recursos audiovisuais a TV, o vídeo cassete (meios passivos) entre outros artefatos que pudessem funcionar como apoio pedagógico ao professor. Nos dias atuais torna-se necessário desenvolver projetos pedagógicos que possam criar possibilidades de possíveis mudanças qualitativas que tais TD podem trazer à prática da construção do conhecimento, e promover o diálogo educativo e social na sociedade contemporânea. Isso porque, atualmente "interagimos" com os conteúdos por meio da Internet e seus serviços.

Trazemos alguns questionamentos e reflexões a partir da análise dos Apps apenas como um mote para despertar o senso crítico do que se lê e o que se colabora e compartilha com os sujeitos em rede a partir destas aplicações contidas ${ }^{14}$ nos dispositivos móveis. A possibilidade de pesquisar, entender e ativar o senso crítico desse processo que a mídia faz/traz conosco também é trabalho para ser pensado e discutido no planejamento pedagógico, no sentido de (re/des) construção do que é divulgado para esses receptores.

Desse modo, o espaço/ambiente de aprendizagem (escola ou fora dela) seja qual for, também falam, expressam e educam. Contudo, a reflexão apresentada traz indícios preliminares passíveis de aprofundamento no contexto da comunicação e aprendizagem ubíqua $^{15}$.

Ao caminharmos para uma representação exploratória, sem grandes presunções de esgotar o assunto, o uso de Apps para o contexto educacional pode auxiliar em possibilidades criativas didático-pedagógica para educar com as mídias. Diante do objeto de investigação, em todos os Apps havia uma "brecha" para compartilhar os conteúdos produzidos a partir das ferramentas de comunicação.

Assim como os demais estudos, o presente trabalho tem também algumas limitações. Uma delas é ter analisado apenas as ferramentas de comunicação. Em estudos futuros será analisado as propagandas publicitárias que contém dentro dos Apps. Há de se entender muitos aspectos educativos e comunicativos nas aplicações, o importante é que possamos desenvolver o senso crítico em como selecionar, analisar e explorar cada tipo de recurso didático tecnológico que esteja relacionado com o projeto pedagógico da escola. E nesse caso acredita-se ser processual no desenvolvimento profissional do professor.

Como bem destaca Freire (1983, p. 46), “A educação é comunicação, é diálogo, na medida em que não é a transferência de saber, mas um encontro de sujeitos interlocutores que buscam a significação dos significados". Desse modo, é preciso atentar-se à relação da comunicação versus educação.

\section{Agradecimentos}

A autora agradece à CAPES/Proex.

\footnotetext{
${ }^{14}$ Para que esses Apps estejam contidos nos equipamentos o usuário necessita "baixar/fazer download" nas lojas online da Apple Store, Google Play ou Windows.

${ }^{15}$ Ver discussão em Santaella (2013).
} 


\section{Referências}

ANDERSON, Lorin W.; KRATHWOHL, David R.; BLOOM, Benjamin Samuel.A taxonomy for learning, teaching, and assessing: A revision of Bloom's taxonomy of educational objectives. 2001. Disponível em: http://www.celt.iastate.edu/pdfsdocs/teaching/RevisedBloomsHandout.pdf - Acesso em out. de 2014.

APP ANNIE. App Analytics Plataform. Disponível em: https://www.appannie.com Acesso em dez. de 2014.

APPLE. Apple Store. Disponível em: https://itunes.apple.com

CARLSSOM, U.; FEILITZEN, C. (Org.). A criança e a mídia: Imagem, Educação, Participação. Brasília: UNESCO, 1999. Disponível em: http://unesdoc.unesco.org/images/0012/001278/127896por.pdf - Acesso em mai. de 2014.

CASTELLS, M. A Sociedade em rede. A era da informação: economia, sociedade e cultura, v.1. Tradução Roneide Venâncio Majer. $7^{\mathrm{a}}$ edição revista e ampliada. São Paulo: Paz e Terra, 2003.

FERRAZ, A. P. C. M.; BELHOT, R. V. Taxonomia de Bloom: revisão teórica e apresentação das adequações do instrumento para definição de objetivos instrucionais. Gest. Prod., São Carlos, v. 17, n. 2, p. 421-431, 2010.

FREIRE, P. Extensão ou Comunicação. São Paulo: Paz e Terra, 1983. . Pedagogia da Autonomia: saberes necessários à prática educativa. São Paulo: Paz e Terra, 1996.

HALL, S. A identidade cultural na pós-modernidade. Rio de Janeiro: DP\&A, 2001.

IBOPE Media. Mobile Report - Aplicativos, ingressos e moda são os itens mais comprados pelo smartphone. Disponível em: http://www.ibope.com.br/ptbr/relacionamento/imprensa/releases/Paginas/Mobile-Report,-do-IBOPE-Media,mostra-habitos-dos-usuarios-de-smartphone.aspx - Acesso em abr. de 2014.

JENKINS, H. Cultura da Convergência. São Paulo: Aleph, 2009.

LÉVY, P. A inteligência coletiva: por uma antropologia do ciberespaço. São Paulo: Edições Loyola, 2011.

LIVI, M. A. C.; SILVEIRA, J. C. S. Introdução à Informática. Universidade Federal do Rio Grande do Sul. 2006. Disponível em:

http://www.inf.ufrgs.br/ alvares/INF01040/ApostilaConceitosBasicos.pdf - Acesso em mai. de 2014.

MORAES, R.; GALIAZZI, M.C. Análise Textual Discursiva. Ijuí: Unijuí, 2007. 
MORAN, J. As mídias na educação. 2007. Disponível em:

http://www.eca.usp.br/prof/moran/site/textos/tecnologias_eduacacao/tecnologias_educ. pdf - Acesso em mai. de 2014.

OFCOM. Children and Parents: Media Use and Attitudes Report. Disponível em: http://stakeholders.ofcom.org.uk/binaries/research/media-literacy/october2013/research07Oct2013.pdf - Acesso em abr. de 2014.

OVERBAUGH, R. C., SCHULTZ, L. Bloom's Taxonomy. 2009. Old Dominion University. Disponível em:

http://ww2.odu.edu/educ/roverbau/Bloom/blooms taxonomy.htm - Acesso em mai. de 2014.

PRENSKY, M. The Role of Technology in teaching and the classroom.

2010. Disponível em: http://www.marcprensky.com/writing/Prensky-

The_Role_of_Technology-ET-11-12-08.pdf - Acesso em jun. de 2014.

SANTAELLA, L. Comunicação ubíqua: Repercussões na cultura e na educação. São Paulo: Paulus, 2013.

SANTOS, F. J. A. O ciberativismo como ferramenta de grandes mobilizações humanas: das revoltas no Oriente Médio às ações pacíficas do Greenpeace no Brasil. [Editorial]. Revista Anagrama: Revista Científica Interdisciplinar da Graduação. set./nov., 2011. Disponível em: http://www.usp.br/anagrama/AnheSantos_ciberativismo.pdf_Acesso em mai. de 2014.

VALLETTA, D. Gui@ de Aplicativos para Educação Básica: Uma investigação associada ao uso de tablets. In A Didática e a Prática de Ensino nas relações entre escola, formação de professores e sociedade, 12. 2014, Fortaleza. Anais. Fortaleza: XVII Encontro Nacional de Didática e Prática de Ensino da ENDIPE. 